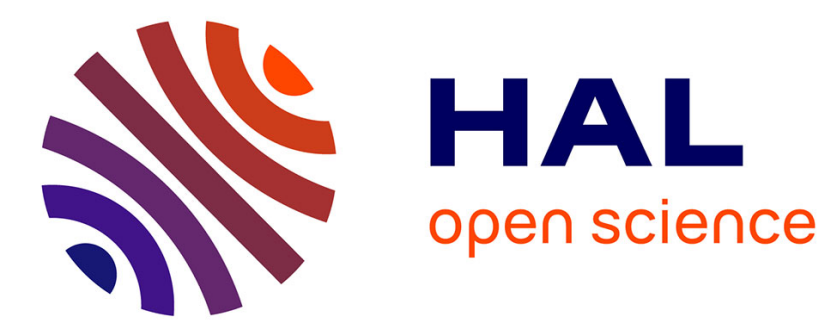

\title{
The performance of a multiple line N2 laser
}

P. Persephonis, B. Giannetas, R. Rigopoulos

\section{To cite this version:}

P. Persephonis, B. Giannetas, R. Rigopoulos. The performance of a multiple line N2 laser. Revue de Physique Appliquée, 1983, 18 (11), pp.731-735. 10.1051/rphysap:019830018011073100 . jpa00245138

\section{HAL Id: jpa-00245138 \\ https://hal.science/jpa-00245138}

Submitted on 1 Jan 1983

HAL is a multi-disciplinary open access archive for the deposit and dissemination of scientific research documents, whether they are published or not. The documents may come from teaching and research institutions in France or abroad, or from public or private research centers.
L'archive ouverte pluridisciplinaire HAL, est destinée au dépôt et à la diffusion de documents scientifiques de niveau recherche, publiés ou non, émanant des établissements d'enseignement et de recherche français ou étrangers, des laboratoires publics ou privés. 


\title{
The performance of a multiple line $\mathbf{N}_{2}$ laser
}

\author{
P. Persephonis, B. Giannetas and R. Rigopoulos \\ Laboratoire de Physique II, Université de Patras, Patras, Greece
}

(Reçu le 6 juin 1983, accepté le 22 juillet 1983)

\begin{abstract}
Résumé. - La diminution de l'inductance du spark-gap du laser à azote décrit dans un article précédent influence la puissance de crête et l'énergie par impulsion, comme suit :

a) elle augmente la puissance de crête d'un laser à azote à double ligne par rapport à celle d'un laser à azote à quadruple ligne, de $58 \%$ au plus, et l'énergie par impulsion de $85 \%$ au plus.

b) la conncection en parallèle à la ligne d'une autre paire de plaques (de telle sorte que la ligne de transmission devienne sextuple), augmente la puissance de crête et l'énergie par impulsion d'à peu près $82 \%$ et $140 \%$ respectivement, par rapport au laser à azote à double ligne.

On examine la limite du nombre de plaques qui peuvent être ajoutées au système, et on prouve qu'elle est limitée par l'inductance du spark-gap.
\end{abstract}

\begin{abstract}
The decrease of the spark-gap inductance of the $\mathrm{N}_{2}$ laser described in a previous paper [1] influences the peak power and the pulse energy as follows :

a) it increases the peak power from double to quadruple line $\mathrm{N}_{2}$ laser up to $58 \%$ and the pulse energy up to $85 \%$.

b) the connection in parallel to the line of another couple of boards (so that the transmission line becomes sixfold), increases the peak power and the pulse energy to about $82 \%$ and $140 \%$ respectively relative to the double line $\mathrm{N}_{2}$ laser.

The limit of the number of boards which may be added in the system is discussed and it is proved limited from the spark-gap inductance.
\end{abstract}

\section{Introduction.}

The effort of many investigators is focused on the peak power increase of a $\mathrm{N}_{2}$ laser [2-6]. The main problem is to put the greatest quantity of electrical energy in the laser tube from the stored energy in the capacitors and in the proper time duration.

The switch system inductance has been discussed widely $[2,3,7,8]$ and it has been proved to be a critical electrical element for both, the peak power and the energy per pulse of the $\mathrm{N}_{2}$ laser. The stored electrical energy in the capacitors also plays a significant rôle.

An increase of the stored electrical energy could be achieved by increasing either the applied voltage or the capacitance of the system.

In the first case it has been proven both theoretically and experimentally that the peak power and the energy per pulse of the laser is proportional to the applied voltage $[3,9,10,11]$.

In the second case, the increase of the capacitance does not result in a similar increase in the peak power and pulse energy $[2,12,13]$. This is attributed to the resonant period of the pulse forming line

$$
T_{1}=2 \pi \sqrt{L_{1} C_{1}}
$$

(namely the part of the system between spark-gap and laser tube in a classical Blumelein line $\mathrm{N}_{2}$ laser) [1].

This resonant period increases by increasing the capacitance for constant value of the inductance. This results in the increase of the current and voltage rise time across the electrodes of the laser tube $[8,12$, $14,15]$. So that the increase of the stored energy in the capacitors does not produce the expected results.

In a previous work [1] the increase of the peak power and pulse energy of the $\mathrm{N}_{2}$ laser by doubling the capacitance of the system and simultaneously decreasing the inductance of the circuit about $40 \%$ of its initial value was reported. So the resonant period $T_{1}=2 \pi \sqrt{L_{1} C_{1}}$ was slightly increased while the rise time of the current and the voltage across the electrodes of the laser tube remained approximately constant. 
This has been achieved by converting a double transmission line $\mathrm{N}_{2}$ laser to a quadruple one.

As a result, the laser tube was fed with more of the stored electrical energy in the capacitors. Thus, the peak power and pulse energy of the quadruple line $\mathrm{N}_{2}$ laser was increased to about $50 \%$ and $70 \%$, respectively.

\section{Experimental part-measurements.}

One of the conclusions of the previous work [1] is that smaller inductance spark-gap, would undoubtedly increase the electrical energy fraction which is transferred to the laser tube during the discharge and consequently increases the percentage of the peak power increase from one couple of boards to two couples.

For the experimental verification of the above, a $\mathrm{N}_{2}$ laser was used, the construction of which is described in [1].

Since then the spark-gap of the system was replaced by another of smaller inductance.

Measurements, similar to the ones reported in [1] for double and quadruple line, were made, in order to compare the results.

This comparison shows that the smaller inductance spark-gap increases the peak power increase from double to quadruple line from about $50 \%$ to about $58 \%$ and also the pulse energy from about $70 \%$ to about $85 \%$.

The last result encouraged the authors to connect another couple of boards in the quadruple transmission line $\mathrm{N}_{2}$ laser. This gave birth to a laser with a sixfold transmission line.

The connection of the boards was made in the same way as for quadruple line [1]. $\mathrm{A} \mathrm{N}_{2}$ laser with a sixfold transmission line can be seen in figure 1 .

The measurements mentioned above were also repeated for the sixfold transmission $\mathrm{N}_{2}$ laser.

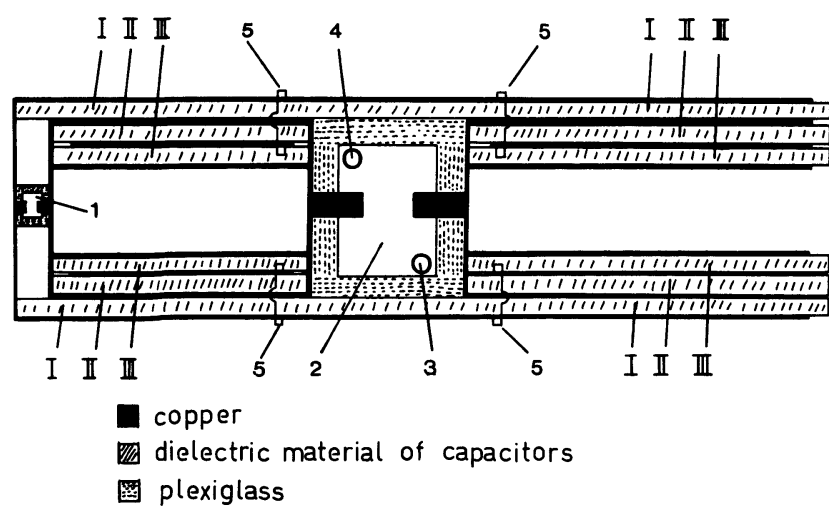

Fig. 1. - Schematic drawing of the quadruple parallelplate transmission line $\mathrm{N}_{2}$ laser. I : the initial double transmission line. II : the additional couple of boards for the quadruple line formation. III : the additional couple of boards for the sixfold line formation. 1 : spark-gap, 2 : laser tube, $3: \mathrm{N}_{2}$ outlet tube, $4: \mathrm{N}_{2}$ inlet tube, $5:$ connections of the equipotential surfaces.
Figure 2 shows an oscillogram of a double transmission line laser pulse, and figure 3 shows an oscillogram of a sixfold transmission line laser pulse.

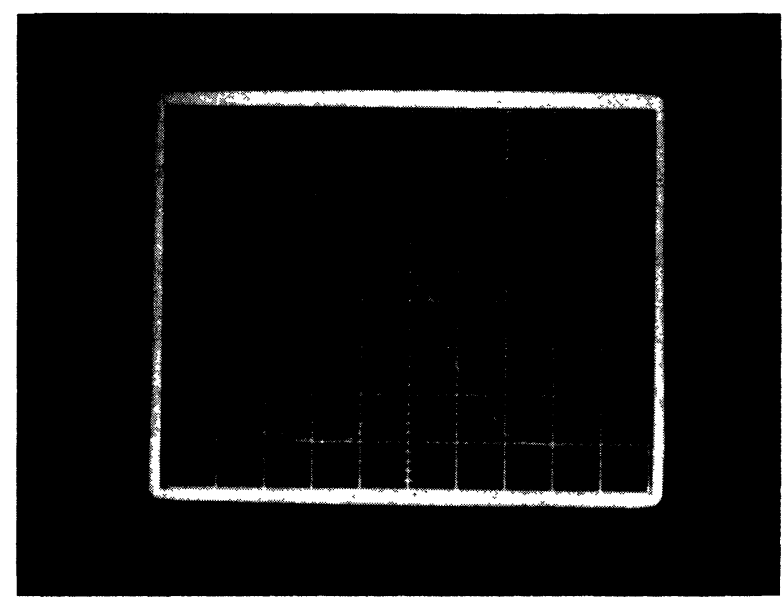

Fig. 2. - Oscillogram of a double line $\mathrm{N}_{2}$ laser pulse : applied voltage $12 \mathrm{kV}$, pressure 110 torr, repetition rate $10 \mathrm{~Hz}$, sweep speed $2 \mathrm{~ns} / \mathrm{div}$.

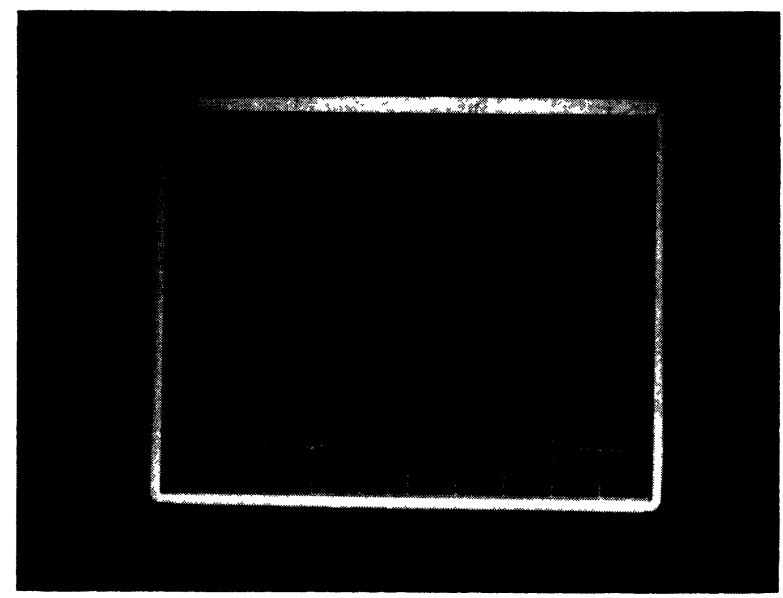

Fig. 3. - Oscillogram of a sixfold line $\mathrm{N}_{2}$ laser pulse : Applied voltage $12 \mathrm{kV}$, pressure 110 torr, repetition rates $10 \mathrm{~Hz}$, sweep $2 \mathrm{~ns} /$ div.

In figure 4 the peak power versus pressure of double quadruple and sixfold transmission line $\mathrm{N}_{2}$ laser, for different voltages (repetition rate $10 \mathrm{~Hz}$ ) is plotted.

Table I shows the percentage increase of the laser peak power from double to sixfold line for different voltages. The pressures correspond to the maxima of the curves of the double and sixfold line in figure 4.

In figure 5 the laser peak power percentage increase from double to sixfold line versus laser tube pressure for different voltages, (repetition rate $10 \mathrm{~Hz}$ ) is given.

Figure 6 shows the peak power versus repetition rate of double quadruple and sixfold transmission line $\mathrm{N}_{2}$ laser for different voltages.

These measurements have been taken with the laser tube pressures corresponding to the maxima of the curves in figure 4. 


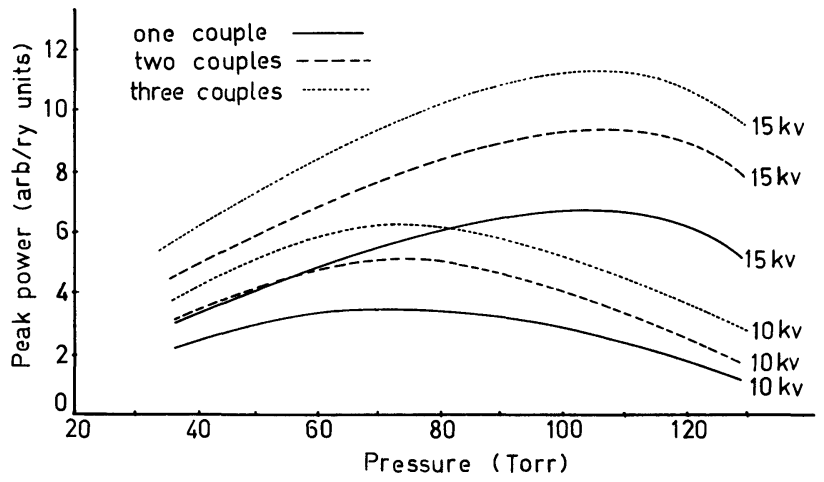

Fig. 4. - Laser peak power versus laser tube pressure for one two and three couples of boards.

Table I. - Increase (\%) of the peak power from double to sixfold line as a function of applied voltage. (Repetition rate $10 \mathrm{~Hz}$.)

\begin{tabular}{|c|c|c|c|c|c|c|}
\hline $\mathrm{kV}$ & 10 & 11 & 12 & 13 & 14 & 15 \\
\hline$\%$ & 82.35 & 80 & 76.35 & 75.25 & 72.85 & 72.3 \\
\hline
\end{tabular}

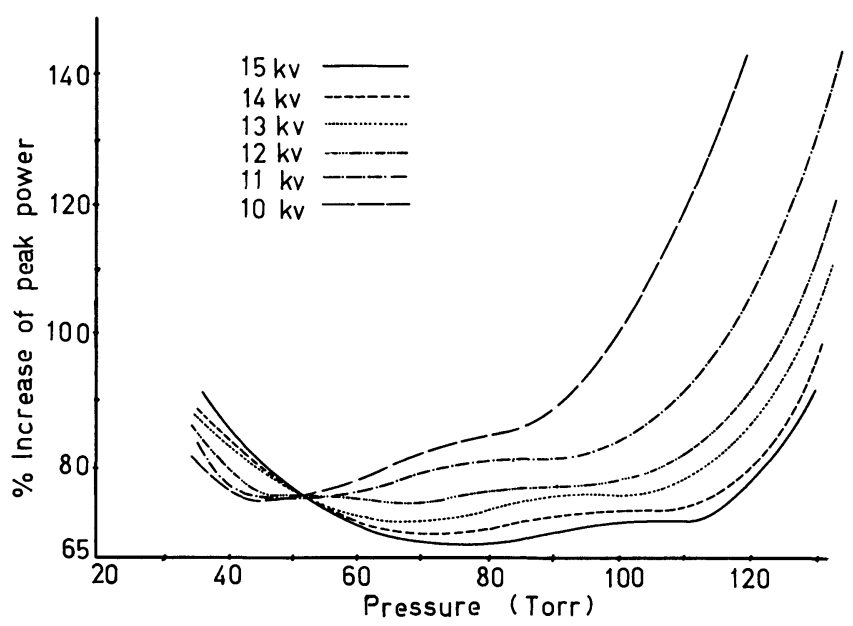

Fig. 5. - Percentage peak power increase from double to sixfold transmission line versus laser tube pressure for different voltages.

Table II shows the percentage increase of the laser peak power from double to sixfold line for different voltages, with repetition rates corresponding to the peaks of the curves of the double and sixfold line in figure 6 .

In figure 7 the laser peak power percentage increase from double to sixfold line versus repetition rates for different applied voltages is given.

The laser pulse duration (FWHM) decreases as the pressure increases from 35 torrs to 130 torrs

from $4 \mathrm{~ns}$ to $3 \mathrm{~ns}$ for the double line

from $4.6 \mathrm{~ns}$ to $3.4 \mathrm{~ns}$ for the quadruple line

from $4.9 \mathrm{~ns}$ to $4 \mathrm{~ns}$ for the sixfold line.
Table II. - Increase (\%) of the peak power from double to sixfold line as a function of applied voltage. (Repetition rate at maxima of Fig. 6.)

\begin{tabular}{|c|c|c|c|c|c|c|}
\hline $\mathrm{kV}$ & 10 & 11 & 12 & 13 & 14 & 15 \\
\hline$\%$ & 125.5 & 102.3 & 87.12 & 78.13 & 69.65 & 64.82 \\
\hline
\end{tabular}

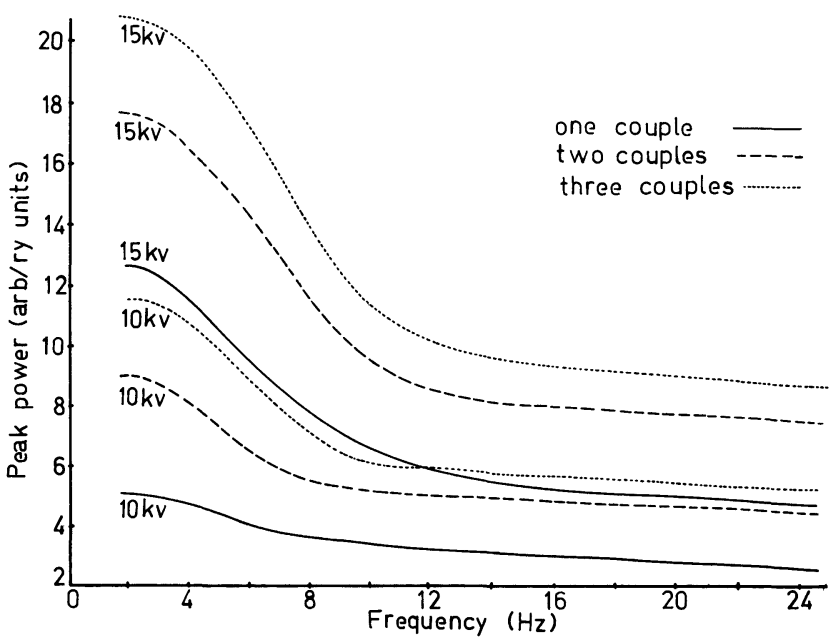

Fig. 6. - Laser peak power versus repetition rate for one, two and three couples of boards.

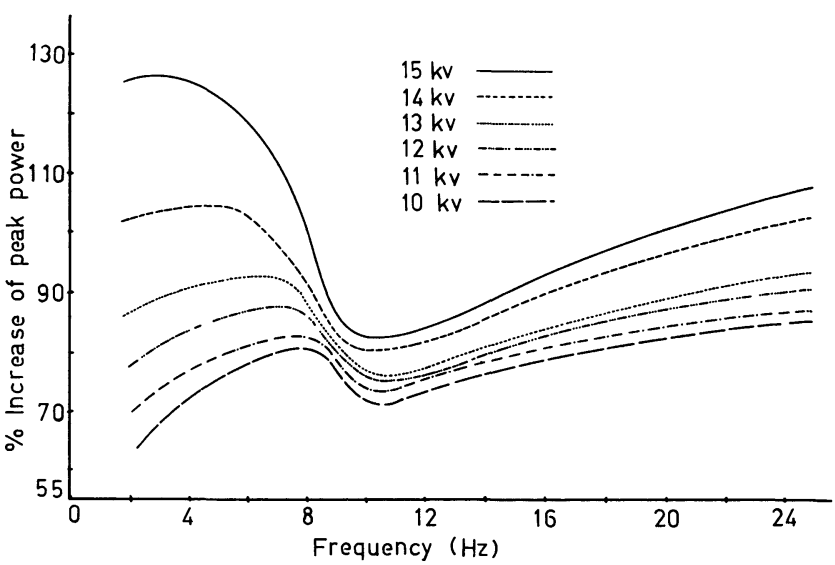

Fig. 7. - Percentage peak power increase from double to sixfold transmission line versus repetition rate for different voltages.

The resonant period of the voltage difference at the electrodes of the laser tube was measured and was found to be :
$41 \mathrm{~ns}$ for the double line
$46 \mathrm{~ns}$ for the quadruple line
$50 \mathrm{~ns}$ for the sixfold line .

\section{Discussion.}

The spark-gap replacement with another one of smaller inductance, decreases the current rise time [10] 
and consequently increases the peak power and pulse energy of the $\mathrm{N}_{2}$ laser. This replacement similarly increases the percentage peak power and energy per pulse increase, when a double line $\mathrm{N}_{2}$ laser is converted to a quadruple line one.

This is explained in [1].

The smaller inductance spark-gap allows the use of a sixfold line without saturation in the peak power. This can be explained as follows :

The inductance $L_{1}$ of the double line circuit, as mentioned in [1], is

$$
L_{1}=L_{\mathrm{c}}+L_{\mathrm{k}}+L_{1}
$$

where, $L_{\mathrm{c}}=$ the constant gap-switch inductance,

$L_{\mathbf{k}}=$ the time varying inductance of the gapswitch discharge channel,

$L_{1}=$ the transmission line inductance plus the stray inductance.

Given that the spark-gap inductance is zero, the inductance $L_{1}$, from relation 2 , degenerates to $L_{1}$. In this case, once the transmission line becomes $2 n$-fold, by connecting $n$ couples of boards, the line capacitance becomes $n C_{1}\left(C_{1}\right.$ : the double line capacitance) and the inductance becomes $\frac{L_{1}}{n}$.

The resonant period remains constant as

$$
T_{1}=2 \pi \sqrt{\frac{L_{1}}{n} n C_{1}}=T_{1}=2 \pi \sqrt{L_{1} C_{1}} \text {. }
$$

Consequently, the current rise time also remains constant. Thus, when the spark-gap inductance is zero, the anode voltage rise time remains constant and independent of the number of the couples of boards connected in parallel.

Therefore, the increase of this number will not result in the laser peak power saturation.

However this cannot happen in practice as the gap-switch inductance is not zero. The spark-gap inductance value is $L_{\mathrm{s}}=L_{\mathrm{c}}+L_{\mathrm{k}}$, where the $L_{\mathrm{k}}$ generally is decreased by increasing the number of the couples of boards, and $L_{\mathrm{c}}$ remains constant [1]. Consequently, the inductance of the circuit becomes higher than the limit value $\frac{L_{1}}{n}$ (zero spark-gap inductance) when $n$ couples of boards are connected. This happens mainly because the $L_{\mathrm{c}}$ value remains constant. So the resonant period increases when $n$ couples of boards are connected to the system. This period will continue to increase, when the number of the boards increases until the peak power saturates. The more the $L_{\mathrm{c}}$ value decreases, the more the total inductance approaches the limit value $\frac{L_{1}}{n}$.

This results in a smaller increase of the resonant period. It means that, for smaller spark-gap inductance, the addition of couples of boards in the system results in a smaller increase of the resonant period.
Consequently, the number of the couples of boards which can be connected to the system, becomes higher until such a point where the value of the peak power saturates.

Figures 2 and 3 show an increase of the peak power of about $80 \%$ from double to sixfold line. The laser pulse duration is $3 \mathrm{~ns}$ and $4.25 \mathrm{~ns}$ for double and sixfold line respectively. So the pulse energy increase, is about $150 \%$ from double to quadruple line.

The curves of the figures $5,6,7$ show differences from the corresponding curves in [1]. These differences are attributed to the spark-gap inductance and they will be discussed elsewhere.

The electrical characteristics of the circuit were calculated in the same manner as in [1]. These are given in table III. As can be seen, the resonant period of the circuit, slightly increases with every new couple of boards, which are added to the system. This is due to the spark-gap inductance, as expected.

Table III. - The electrical characteristics of the $\mathrm{N}_{2}$ laser system.

\begin{tabular}{|l|r|r|r|r|l|}
\hline \multicolumn{1}{|c|}{$\begin{array}{c}Z \\
\Omega\end{array}$} & $\begin{array}{c}C_{1} \\
\mathrm{nF}\end{array}$ & $\begin{array}{c}C_{2} \\
\mathrm{nF}\end{array}$ & $\begin{array}{c}T_{1} \\
\mathrm{~ns}\end{array}$ & $\begin{array}{c}L_{1} \\
\mathrm{nH}\end{array}$ & \multicolumn{1}{|c|}{$\begin{array}{c}\text { multiplicity } \\
\text { of the line }\end{array}$} \\
\hline 0.182 & 8 & 24.4 & 41 & 5.316 & double line \\
0.09125 & 16 & 48.8 & 46 & 3.346 & quadruple line \\
0.0606 & 24 & 73.2 & 50 & 2.635 & sixfold line \\
\hline
\end{tabular}

This small increase of the resonant period increases the current rise time and consequently decreases the laser efficiency. Thus the number of boards which it is possible to connect to the laser transmission line (for the same spark-gap) is restricted.

\section{Conclusions.}

The spark-gap replacement by another of smaller inductance than the initial one, increases the peak power and pulse energy from double to quadruple transmission line. Thus the average increase of the peak power is altered from about $50 \%$ [1] to $58 \%$ and the average increase of the energy per pulse is altered from about $70 \%$ to $85 \%$.

This allows the connection of another couple of boards at the quadruple line and so the line becomes sixfold. The average value of the laser peak power increases from about $58 \%$ to about $82 \%$ and the average value of the laser pulse energy also increases from $85 \%$ to $140 \%$ relatively to the peak power and pulse energy of the double transmission line.

In general the spark-gap inductance restricts the couples of boards number which can be connected in parallel to the system. Smaller spark-gap inductance allows larger number of couples of boards to be connected to the system. 


\section{References}

[1] Persephonis, P. et al., Revue Phys. Appl. 18 (1983) 295-300.

[2] Ali, A. W. et al., Appl. Opt. 8 (1969) 993-996.

[3] Basting, D. et al., Opto-electronics 4 (1972) 43-49.

[4] Levatter, J. et al., Appl. Phys. Lett. 25 (1974) 703-705.

[5] Spyroy, N. et al., Revue Phys. Appl. 15 (1980) 1459. 1467.

[6] Hilborn, R. C., Am. J. Phys. 44 (1976) 1172-1176.

[7] IWASAKI, C. et al., I.E.E.E. J. Quantum Electron. QE-18 (1982) 423-427.

[8] SchwaB, A. J., I.E.E.E. J. Quantum Electron. QE-12 (1976) 183-188.
[9] Geller, M. et al., Appl. Opt. 1 (1968) 2232-2237.

[10] WoOdWARD, B. W. et al., Rev. Sci. Instrum. 44 (1973) 882-887.

[11] Richter, P. et al., Appl. Opt. 15 (1976) 756-760.

[12] Fitzsimmons, W. A. et al., I.E.E.E. J. Quantum Electron. QE-12 (1976) 624-633.

[13] Stanciulescu, C. et al., Rev. Roum. Phys. 24 (1979) 21-25.

[14] Andersson, H. et al., Opto-electronics 6 (1974) 225 234.

[15] Sidorov, Yu. L. et al., Sov. J. Quantum Electron. 8 (3) (1978) 334-339. 